\title{
Maternal-Fetal Prognosis of the Prophylactic Cesaarian versus Emergency Cesaarian at the Reference Health Center of Commune V of Bamako District, Mali
}

\author{
Cheickna Sylla ${ }^{1,2 *}$, Soumano Oumar Traoré ${ }^{1,3}$, Alassane Traoré ${ }^{4}$, Alou Samaké5, Saleck Doumbia ${ }^{1}$, \\ Saoudatou Tall1, Belco Tamboura1, Sitapha Dembélé6, Seydou Z. Dao7 ${ }^{7}$, Ibrahima Teguétée,8, \\ Youssouf Traoréé,8, Niani Mounkoro ${ }^{3,8}$, Mamadou Traoré1,3, Amadou Ingré Dolo ${ }^{3,8}$ \\ ${ }^{1}$ Department of Gynecology and Obstetrics, Reference Health Centre of Commune V, Bamako, Mali \\ ${ }^{2}$ Department of Obstetrics and Gynecology, Koutiala Reference Health Centre, Sikasso, Mali \\ ${ }^{3}$ Faculty of Medicine and Odontostomatology, University of Sciences, Techniques and Technologies, Bamako, Mali \\ ${ }^{4}$ Mali Hospital, Bamako, Mali \\ ${ }^{5}$ Department of Gynecology and Obstetrics, Reference Health Centre of Commune VI, Bamako, Mali \\ ${ }^{6}$ Department of Gynecology and Obstetrics, Hospital of Kayes, Kayes, Mali \\ ${ }^{7}$ Department of Gynecology and Obstetrics, Reference Health Centre of Commune II, Bamako, Mali \\ ${ }^{8}$ Department of Gynecology and Obstetrics, Gabriel Touré University Hospital, Bamako, Mali \\ Email: *scheickylla@yahoo.fr
}

How to cite this paper: Sylla, C., Traoré, S.O., Traoré, A., Samaké, A., Doumbia, S., Tall, S., Tamboura, B., Dembélé, S., Dao, S.Z., Teguété, I., Traoré, Y., Mounkoro, N., Traoré, M. and Dolo, A.I. (2020) Maternal-Fetal Prognosis of the Prophylactic Cesaarian versus Emergency Cesaarian at the Reference Health Center of Commune V of Bamako District, Mali. Surgical Science, $11,329-341$.

https://doi.org/10.4236/ss.2020.1110034

Received: September 8, 2020

Accepted: October 27, 2020

Published: October 30, 2020

Copyright $\odot 2020$ by author(s) and Scientific Research Publishing Inc. This work is licensed under the Creative Commons Attribution International License (CC BY 4.0).

http://creativecommons.org/licenses/by/4.0/

\begin{abstract}
Objectives: The goal was to assess the risk factors for emergency cesarean section versus prophylactic caesarean section. Materials and Methods: This was a descriptive analytical cross-sectional study of the Type Cas/Witnesses at the Reference Health Centre of Commune V of the District of Bamako in Mali. The sample consisted of 100 cases for 200 controls ( 1 case for 2 controls) with retrospective collection of data for the period from January 1 to July 11 , 2011 (6 months and 11 days). Results: During the study period, out of a total of 3559 deliveries, we recorded 2,794 vaginal deliveries, $78.50 \%$ and 765 caesarean sections or $21.50 \%$. Of the 765 ceras, we performed 353 emergency caesarean sections or $46.15 \%$ and 412 prophylactic caesarean sections $53.85 \%$. We have selected 100 prophylactic caesarean section files and 200 emergency caesarean section files. The average age of the patients was 27.41 years-5.84 with extreme ages of 14 to 40 years. $100 \%$ of our patients (Cas) had performed at least one antenatal consultation compared to $83.5 \%$ of the parturients evacuated (Witnesses). The most frequently cited reasons for evacuation were: acute fetal suffering, non-cephalic presentation and excessive uterine height with $30 \%, 17.5 \%$ and $12 \%$ respectively. The bulk of the caesarean
\end{abstract}


section indications were dominated by dystocies with $90 \%$ in cases compared to $65 \%$ in Witnesses, followed by acute fetal suffering with $30 \%$ in Witnesses. We recorded $30 \%$ perinatal deaths among Witnesses compared to $1 \%$ in Cases. We recorded 16 uterine ruptures in the Witnesses among which 2 hysterectomies and 14 hystererraphia. Conclusion: Prophylactic caesarean section improves maternal and perinatal prognosis more than emergency caesarean section.

\section{Keywords}

Caesarean, Frequency, Evacuation, Maternal-Fetal Prognosis

\section{Introduction}

\subsection{Background}

Pregnancy and childbirth have been a fatal risk to women since the beginning of times, Rivière said in 1959 [1]. This assertion of River is still relevant.

This risk that haunts every obstetrician explains the ongoing research to achieve the best pathways for a favorable outcome of pregnancy and childbirth.

In Mali, the direct estimate of the maternal mortality rate for the period 1989-1996 was 577 maternal deaths per 100,000 live births [2]. This rate is still too high despite all the current significant efforts to reduce this rate, which has hardly changed. In 2001 this rate was estimated at 582 maternal deaths per 100,000 live births [3]. Currently, the maternal mortality rate is 368 maternal deaths per 100,000 live births (EDS5 Mali 2012). Malian society continues to pay a heavy price for poor treatment of pregnancy and childbirth. Apart from haemorrhages, which account for $25 \%$, infections $15 \%$, pre-eclampsia and eclampsia $13 \%$, abortions $13 \%$, dystocia occupies a significant place with $7 \%$ of direct obstetric causes [4]. As early as 1986, with the "Lower Risk Maternity" initiative, the World Health Organization (WHO) advocated that surveillance of childbirth and early detection of dystocies be taken as one of the most important approaches to reducing maternal mortality [5]. The proposal to use caesarean section to continuously improve the quality of obstetric care meets these priorities.

Whether programmed or done in an emergency, caesarean section is now a very practiced and well-controlled delivery technique. However, the risks and discomforts caused by this surgical procedure, so feared by pregnant women, should not be minimized. However, emergency caesarean section is more at risk because of the lack of preparation of the parturients and the surgical emergency. In recent years, caesarean section indications have evolved resulting in a steady increase in its frequency. This increase in frequency is related to the birth attendant's concern to give birth to the newborn in the best possible condition and a healthy mother [6]. Camara K. [7] in 2010 at the same centre found 614 caesarean sections, of which 217 were emergency caesareans, or $35.35 \%$ and 397 
prophylactic caesarean sections or $64.65 \%$.

Today, parturients, who are normally required to benefit from prophylactic caesarean section, are still held in our labour rooms where they are subjected to severe labour tests by unskilled personnel, resulting in a poor fetal and neonatal maternal prognosis. With this in mind, we decided to initiate this work in order to objectively assess the extent of the problem in terms of maternal and fetal prognosis.

Is the maternal-fetal prognosis of emergency caesarean section more at risk than prophylactic caesarean section?

\subsection{Objectives}

The aim was to assess the risk factors for emergency cesarean section versus prophylactic caesarean section at the reference health centre in Commune $\mathrm{V}$ of Bamako district in Mali.

\section{Materials and Methods}

This was a descriptive study, Cross-sectional and analytical Cas/Witnesses (1Cas for 2 Witnesses) with age and parity matching, with a retrospective collection of data from January 1 to July 11, 2011 (i.e. 6 months and 11 days) in the obstetrics and gynecological department of the Commune V Reference Health Centre in Bamako District, Mali. The study population: all patients who gave birth and accepted the study with informed consent during the study period. Sampling: We conducted a non-exhaustive sampling of all caesarean section cases. Sampling technique: Cases and controls were selected by pairing case; age-to-parity matching criteria. Sample size: Our study involved 100 cases of prophylactic caesarean section and 200 Emergency Caesarean Controls (300 patients).

\subsection{Inclusion Criteria}

Cases: All patients who received a prophylactic caesarean section were included in our study. Witnesses: Any patient evacuated to the V-shared reference health centre who was diagnosed with a $4 \mathrm{~cm}$ cervical dilation and who was given an emergency caesarean section after the entrance examination concluded that they had been given a $4 \mathrm{~cm}$ cervical dilation.

\subsection{The Non-Inclusion Criteria}

Not included in our study were all caesarean patients in the ward who did not meet our inclusion criteria. Data collection and support: The following information was collected on the following documents: birth registry; C-section registry; obstetric records; Reference register/evacuations; a register of operational reports; Newborn transfer registry; perinatal death registry; maternal death registry; anaesthesia registry. The variables studied were age, occupation, marital status, medical and surgical history, concept of prenatal consultation, caesarean section indications, nature of intervention, maternal-fetal prognosis. 


\subsection{The Limitations of the Study}

Some scheduled caesarean sections return to labour before the scheduled date and give birth vaginally or are taken by emergency caesarean section. Some emergency caesarean sections give birth in the O.R. Are the conditions of newborns influenced by these deliveries?

\subsection{Data Analysis}

The data was entered and analyzed on the Epi-Info version 6.04 software in accordance with the formula applicable to the case/control study. The statistical test used was the Odds ratio (OR) to study associations between variables. The probability (p) was determined with an alpha risk of $5 \%$. An $\mathrm{OR}<1$ was associated with protection against the phenomenon studied; OR $\geq 2$ was more synonymous with a worsening of the phenomenon studied.

\section{Results}

During the study period, out of a total of 3559 deliveries, we recorded 2794 vaginal deliveries, $78.50 \%$ and 765 caesarean sections or $21.50 \%$. Of the 765 ceras, we performed 353 emergency caesarean sections or $46.15 \%$ and 412 prophylactic caesarean sections $53.85 \%$. We have selected 100 prophylactic caesarean section files and 200 emergency caesarean section files.

\subsection{Epidemiological Aspects}

The 20 - 34 age group was the most represented (73\%) with an average age in both groups of 27.41 years - 5.84. Figure 1 shows us the distribution of patients by age. Marital status: In our study, $97 \%$ of cases were married versus $89 \%$ of Witnesses. Occupation: Housewives accounted for 52\% for Cases and $73 \%$ for Witnesses. Women's residence: Most of the women in our study resided in

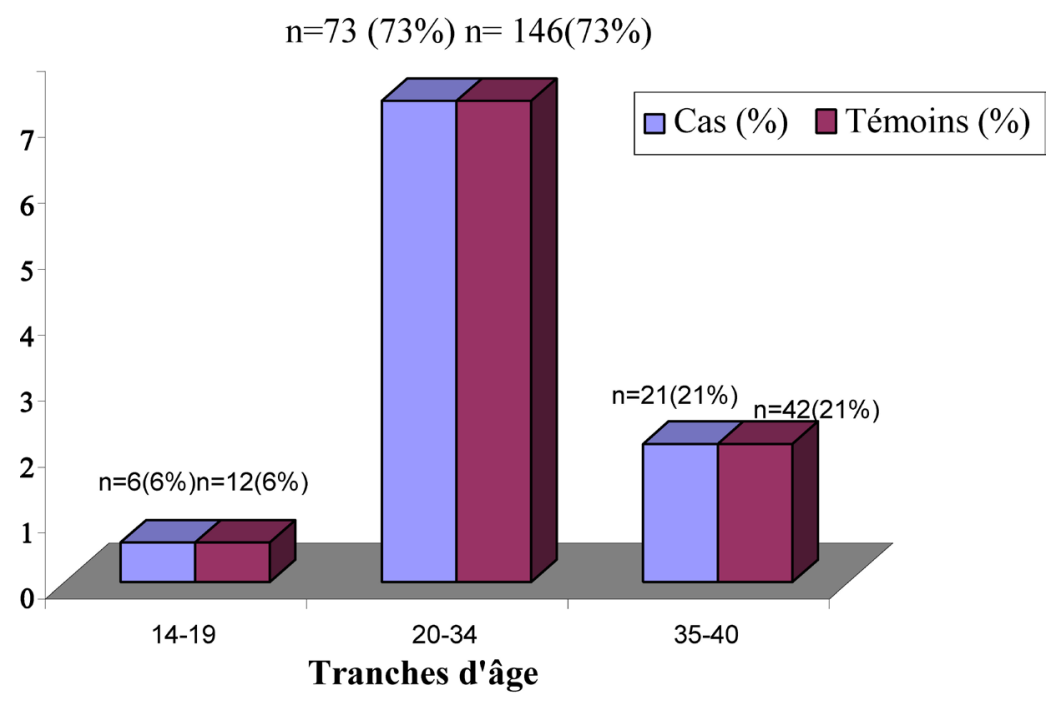

Figure 1. Distribution of caesarean patients by age at the reference health centre in commune V of Bamako district, Mali from January 1 to July 11, 2011. 
commune V of Bamako district; $66 \%$ for Cases and $68.5 \%$ for Witnesses. Epidemiological aspects are summarized in Figure 1 and Table 1.

\subsection{Clinical Aspects}

\subsubsection{Medical-Surgical History and Pregnancy Monitoring}

Maternal pathologies (HTA, Diabetes, Sickerocytosis) were found in 6\% of cases and $4.5 \%$ of Witnesses. Surgical history: The history of caesarean section was found in $71 \%$ of cases and in $34 \%$ of Witnesses. The indications of the anterior cesarean section: Dystocia dominated with a frequency of $73.2 \%$ for cases compared to $44.2 \%$ for Witnesses. Acute fetal suffering was the second indication found with a rate of $25.4 \%$ for Cases and $52.9 \%$ for Witnesses. The inter-reproductive interval: greater than 2 years was the most represented with $83 \%$ for Cases and $86.5 \%$ for Witnesses. Prenatal consultation: $100 \%$ of cases performed at least one antenatal consultation compared to $83.5 \%$ of Witnesses. This history and pregnancy follow-up are shown in Table 2.

\subsubsection{The Nature of the Intervention}

We recorded 16 uterine ruptures in the Witnesses (evacuated parturients); of the 16 uterine ruptures 14 had hystererrapphic and 2 had hysterectomy. None of her complications were found in the Cases (prophylactic caesarean section).

\subsubsection{The Indications of Caesarean Section}

Bone dystocia was the main maternal indication of caesarean section with $90 \%$ of our caesarean section indications in Cases versus $60 \%$ in Witnesses and acute fetal suffering was the main fetal indication of cesarean section with a frequency

Table 1. Breakdown of Caesarean patients according to epidemiological aspects at the reference health centre in commune V of Bamako district, Mali from January 1 to July 11, 2011.

\begin{tabular}{cccccccc}
\hline & \multicolumn{2}{c}{ Cases } & \multicolumn{2}{c}{ witnesses } & & OR & IC \\
\cline { 2 - 4 } & $\mathbf{N}$ & $\%$ & $\mathbf{N}$ & $\%$ & & & \\
\hline Marital status & & & & & & & \\
Married & 97 & 97 & 178 & 89 & 0.018 & 4.00 & {$[1.15-21.30]$} \\
Single & 3 & 3 & 22 & 11 & & & \\
Profession & & & & & & & \\
Housewife & 52 & 52 & 146 & 73 & 0.0002 & 0.40 & {$[0.24-0.68]$} \\
Official & 25 & 25 & 5 & 2.5 & $10^{-7}$ & 13.00 & {$[4.62-44.68]$} \\
Student & 9 & 9 & 29 & 14.5 & 0.176 & 0.58 & {$[0.23-1.34]$} \\
Trade & 8 & 8 & 15 & 7.5 & 0.928 & 1.018 & {$[0.36-2.64]$} \\
Other & 6 & 6 & 5 & 2.5 & 0.128 & 2.49 & {$[0.61-10.56]$} \\
Residence & & & & & & & \\
Common V & 66 & 66 & 137 & 68.5 & 0.662 & 0.89 & {$[0.52-1.54]$} \\
Other municipalities & 34 & 34 & 63 & 31.5 & & & \\
\hline
\end{tabular}


of $30 \%$ in Witnesses. Scarring uteruses were found in $10 \%$ of cases and preeclampsia in $5 \%$ of Witnesses.

The nature of the procedure and the indications of caesarean sections are summarized in Table 3.

\subsection{Maternal-Fetal and Early Neonatal Prognosis}

\subsubsection{Maternal Prognosis}

Post-operative complications: hemorrhagic/anaemia complications were most

Table 2. Breakdown of Caesarean patients based on medical-surgical history and pregnancy monitoring at the reference health centre in commune $\mathrm{V}$ in Bamako district, Mali from January 1 to July 11, 2011.

\begin{tabular}{|c|c|c|c|c|c|c|c|}
\hline \multirow{2}{*}{$\frac{\text { Caesarean section indication Previous }}{\text { Dystocia }}$} & \multicolumn{2}{|c|}{ Cases } & \multicolumn{2}{|c|}{ Witnesses } & \multirow{2}{*}{$\begin{array}{c}\mathbf{P} \\
0.0036\end{array}$} & \multirow{2}{*}{$\begin{array}{l}\text { OR } \\
3.47\end{array}$} & \multirow{2}{*}{$\frac{\text { IC }}{[1.35-8.92]}$} \\
\hline & 52 & 73.2 & 15 & 44.2 & & & \\
\hline triple pregnancy & 1 & 1.4 & 0 & 0 & - & - & \\
\hline acute fetal suffering & 18 & 25.4 & 18 & 52.9 & 0.0053 & 0.30 & {$[0.12-0.78]$} \\
\hline Bleeding & 0 & 0 & 1 & 2.9 & & - & \\
\hline \multicolumn{8}{|l|}{ Inter-reproductive interval } \\
\hline$<2$ & 17 & 17 & 27 & 17 & & & \\
\hline$>2$ & 83 & 83 & 173 & 83 & & & \\
\hline \multicolumn{8}{|l|}{ Prenatal consultation } \\
\hline Yes & 100 & 100 & 167 & 83.5 & 0.000016 & & \\
\hline Not & 0 & 0 & 33 & 16.5 & & & \\
\hline \multicolumn{8}{|l|}{$\begin{array}{l}\text { Qualification of the author } \\
\text { of the prenatal }\end{array}$} \\
\hline Qualified staff & 100 & 100 & 140 & 70 & $10^{-7}$ & & \\
\hline Unqualified staff & 0 & 0 & 27 & 13.5 & 0.0001 & 0.00 & {$[0.00-0.26]$} \\
\hline No & 0 & 0 & 33 & 16.5 & - & & \\
\hline
\end{tabular}

Table 3. Breakdown of Caesarean patients according to the nature of the procedure and the indications of caesarean sections at the reference health centre of Commune V of Bamako district in Mali from January 1 to July 11, 2011.

\begin{tabular}{|c|c|c|c|c|c|c|}
\hline & \multicolumn{2}{|c|}{ Cases } & \multicolumn{2}{|c|}{ witnesses } & $\mathbf{P}$ & OR \\
\hline Simple Caesarean & 100 & 100 & 184 & 92 & 0.0036 & \\
\hline Hystererraphia/Hysterectomies & 0 & 0 & 16 & 8 & & \\
\hline \multicolumn{7}{|l|}{ Indications of caesarean sections } \\
\hline Bone dystocia & 90 & 90 & 130 & 65 & $10^{-7}$ & 17.41 \\
\hline Acute fetal suffering & 0 & 0 & 60 & 30 & $10^{-7}$ & 0.00 \\
\hline Preeclampsia & 0 & 0 & 10 & 5 & $10^{-7}$ & 0.00 \\
\hline Scarred uterus & 10 & 10 & 0 & 0 & - & \\
\hline
\end{tabular}


represented, followed by infectious complications with $15.5 \%$ and $12.5 \%$ respectively in The Controls.

We did not record maternal deaths in the two groups: Cases and Witnesses.

\subsubsection{Fetal Prognosis: Mortality and Morbidity}

72.5\% of The Witness's newborns were in a state of severe morbidity or born deaths (Apgar score between 0 - 7) and 27.5\% had a good Apgar between 8 - 10 in the first year unlike the Cases, the $100 \%$ had an Apgar between $8-10$ and $1^{\text {st }}$ mn. Neonatal death: we recorded $30 \%$ of perinatal deaths among Witnesses compared to $1 \%$ in Cases. Table 4 summarizes the maternal-fetal and early neonatal prognosis and Figure 2 represents post-operative maternal complications.

Table 4. Early maternal-fetal and neonatal prognosis of Caesarean patients at the reference health centre in commune V of Bamako district, Mali from January 1 to July 11, 2011.

\begin{tabular}{cccccccc}
\hline Maternal prognosis & \multicolumn{2}{c}{ Cases } & witnesses & P & OR & IC \\
\hline Obstetric haemorrhage & 0 & 0 & 2 & & $10^{-7}$ & 0.02 & {$[0.00-0.14]$} \\
Hysterectomy & 0 & 0 & 2 & 1 & & & \\
Maternal death & 0 & 0 & 0 & 0 & & & \\
Apgar score & & & & & & & \\
0 - 7 (stillborn, morbidity) & 0 & 0 & 145 & 21.5 & $10^{-7}$ & 0.00 & {$[0.00-0.02]$} \\
8 - 10 (alive, good Apgar) & 100 & 100 & 55 & 51 & & & \\
Early neonatal death & & & & & & & \\
Yes & 1 & 1 & 17 & 10.8 & 0.0026 & 0.08 & {$[0.00-0.55]$} \\
Not & 99 & 99 & 140 & 89.2 & & & \\
\hline
\end{tabular}

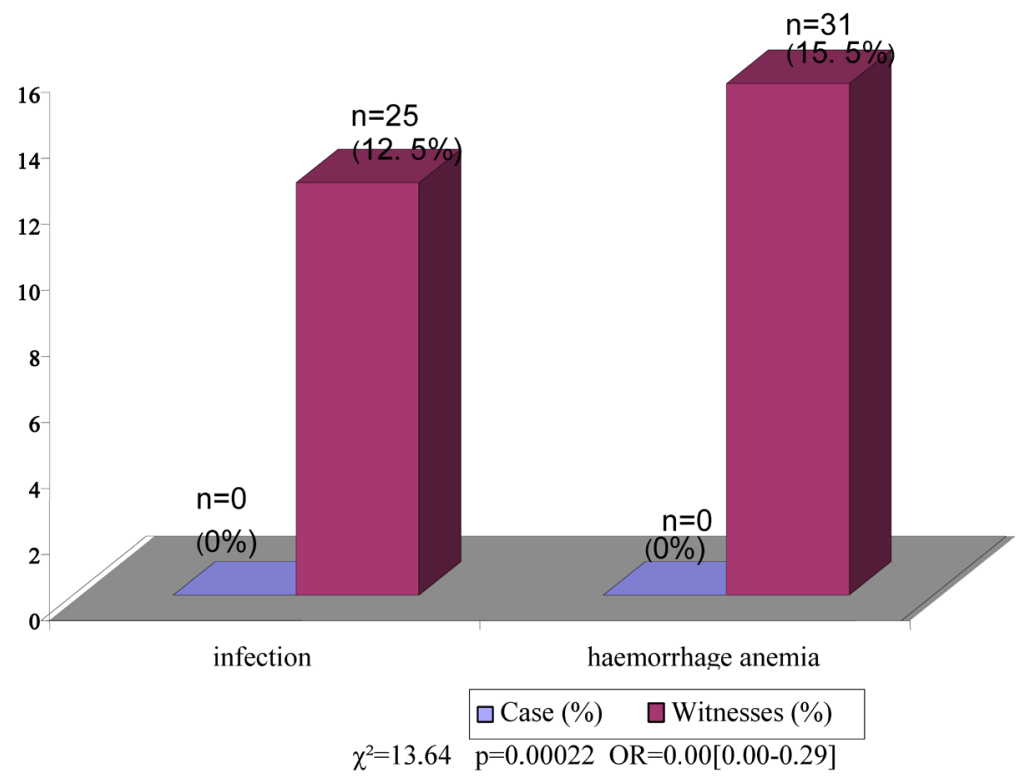

Figure 2. Distribution of caesarean patients according to post-operative maternal complications at the reference health centre in commune $\mathrm{V}$ of Bamako district, Mali from January 1 to July 11, 2011. 


\subsection{Length of Hospitalization}

$100 \%$ of cases had a hospital duration of three days or less compared to $46 \%$ of Witnesses. 54\% of Witnesses had a hospital duration of more than 3 days. The average length of hospitalization in the cases was 2.01 days -0.1 with extremes of 2 and 3 days. The average length of hospitalization for Witnesses was 4.9 days - 3.1 with extrêmes de 2 et 20 jours. Figure 3 shows us the length of hospital stay.

\section{Discussion}

In the literature, Camara K. [7] in 2010 in the same centre had found 614 caesarean sections of which 217 emergency caesareans or $35.35 \%$ and 397 prophylactic caesarean sections or $64.65 \%$. Our study reports from the study period, out of a total of 3559 deliveries, we recorded 2794 vaginal deliveries or $78.50 \%$ and 765 caesarean sections or $21.50 \%$. Of the 765 ceras, we performed 353 emergency caesarean sections or $46.15 \%$ and 412 prophylactic caesarean sections $53.85 \%$. We have selected 100 prophylactic caesarean section files and 200 emergency caesarean section files.

Other studies conducted by Coulibaly I. [8]; and Togora M. [9] at the reference health centre of Commune $\mathrm{V}$ had found $12.17 \%$ and $12.88 \%$ respectively. In 1993, A Tégueté I. [10] reported a frequency of $24.05 \%$ in a study carried out at the Gabriel Touré University Hospital from 1991 to 1993. According to Mali's National Directorate of Health in 2005 [11] nationally, caesarean deliveries occupy a rate of $0.9 \%$.

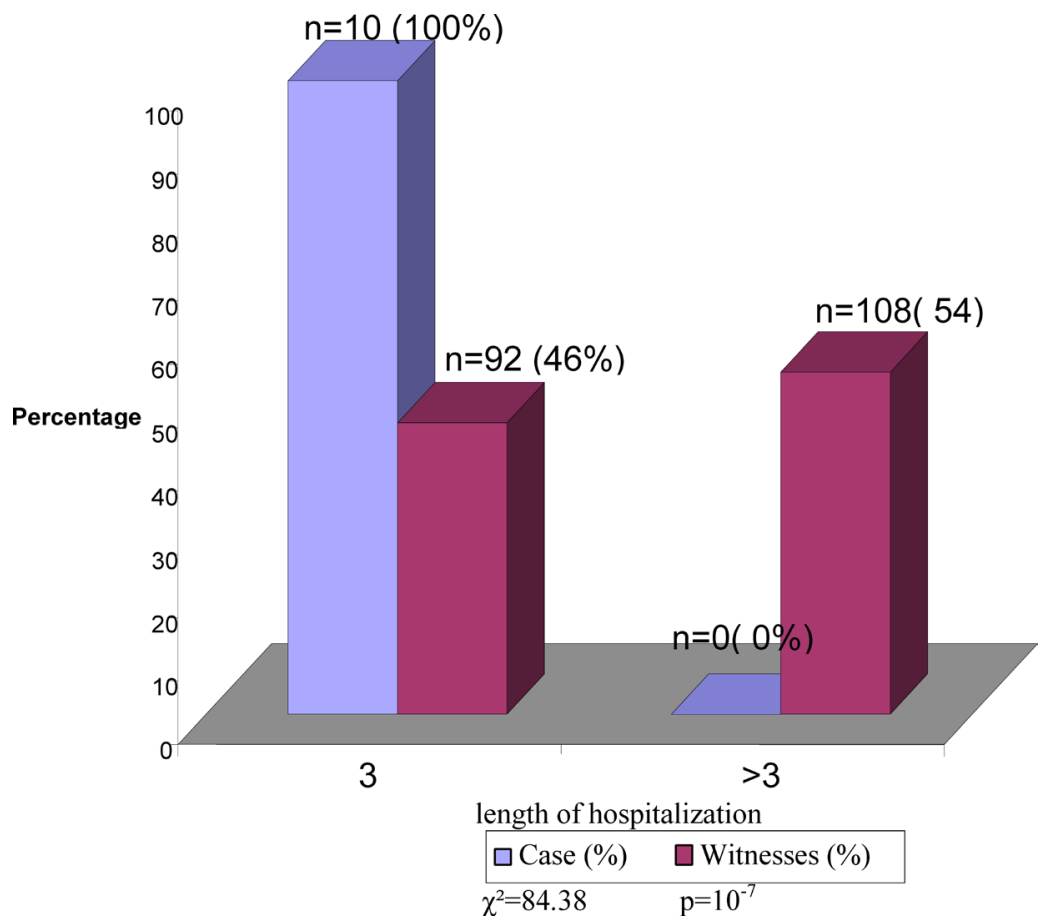

Figure 3. Breakdown by length of hospitalization of Caesarean patients at the reference health centre in the commune V of Bamako district, Mali from January 1 to July 11, 2011. 


\subsection{Epidemiological Aspects}

The 20 - 34 age group was the most represented, with $73 \%$ with an average age of 27.41. The same trends were reported by other authors for the same age group: 71\% for Sissoko H. [12]; 61.17\% for Cissé B. [13] and 51\% for Camara K. [7]. This is the optimal age of fertility en Afrique au sud du Sahara. Marital status: in our study, $97 \%$ of cases were married compared to $89 \%$ of Witnesses, with a statistically significant difference with [p-0.018; OR-4.00 [11,521.30]. Tegueté I. [10] and Cissé B. [13] had found $91.58 \%$ and $90.7 \%$ of brides respectively. Married women have more access to antenatal care. Occupation: The professional occupations of patients can be a barrier to access to care. For example, some professional orders are highly exposed: Housewives accounted for $52 \%$ for Cases and 73\% for Witnesses with p-0.0002; GOLD-0.40 [0.24 - 0.68]. The same trends were reported by Konaté M. [14] in 2001 with 53.6\% per Tegueté I. [10] in 1993 with $86.01 \%$. Officials had more access to prophylactic caesarean section with a statistically significant difference with P-lt; 10 - 7; GOLD-13 [4.62 - 44.68].

\subsection{Clinical Aspects}

\section{Medical-surgical history and pregnancy monitoring}

Medical history (HTA, Diabetes, Sickerocytosis): Maternal pathology was found in $6 \%$ of cases and $4.5 \%$ of Witnesses with p-0.574, OR 1.35 [0.38 - 4.40].

Medical history (HTA, Diabetes, Sickerocytosis): in our study maternal pathology was found in $6 \%$ of cases and $4.5 \%$ of Witnesses with p-0.574, OR 1.35 [0.38 - 4.40]. Surgical history: A history of caesarean section was found in $71 \%$ of cases and $34 \%$ of Witnesses with a statistically significant difference (p-10-7 OR-11.95 [6.53 - 21.98]). The indications of the anterior caesarean section: Dystocia dominated with a frequency of $73.2 \%$ for cases compared to $44.2 \%$ for Witnesses with a statistically significant difference (p-0.0036 OR 3.47 [1.35 8.92]). Acute fetal suffering was the second indication found with $\mathrm{p}-0.0053$, OR-0.30 [0.12 - 0.78]. Inter-reproductive invalle: The inter-reproductive interval greater than 2 years was most represented with $83 \%$ for Cases and $86.5 \%$ for Witnesses, and the difference is not statistically significant (p-0.419, OR 1.31 [0.63 - 2.66]). Prenatal performance: $100 \%$ of cases performed at least one antenatal consultation compared to $83.5 \%$ of Witnesses with a statistically significant difference of 0.000016 . Authors of the antenatal consultation: $100 \%$ of cases were followed by qualified staff compared to $70 \%$ for Witnesses with a statistically significant difference with p-10 $0^{-7} .13 .5 \%$ of Witnesses were followed by unskilled staff. Camara K. [7] had found $13 \%$ followed by unskilled staff. $16.5 \%$ of Witnesses had not performed any antenatal visits. Women's residence: Most of the women in our study resided in commune $\mathrm{V}$ of Bamako district; $66 \%$ for Cases and $68.5 \%$ for Witnesses. Some authors have reported the following results: Sissoko H. [12]); 71.1\% for Cases and Camara K. [7] 78\% for Cases $86.5 \%$ for Witnesses. But $34 \%$ of the cases and $31.5 \%$ of the Witnesses resided outside the 
commune V, Sissoko H. [12] had found $17.8 \%$. This is due to the fact that the reference health centre of commune $\mathrm{V}$ receives a lot of the cases of references and evacuations. There is no statistically significant difference in $\mathrm{p}-0.662 \mathrm{OR}$ $-0.89[0.52-1.54]$.

\subsection{The Nature of the Procedure and the Indications of Caesarean Sections}

\subsubsection{The Nature of the Intervention}

We recorded 16 uterine ruptures in the Witnesses (evacuated parturients); of the 16 uterine ruptures 14 had hystererraphia and 2 had hysterectomy. None of her complications were found in the Cases (prophylactic caesarean section).

\subsubsection{The Indications of Cesarean Sections}

In our study several indications of caesarean section were noted, they are either maternal or fetal. Through the evolution of caesarean section indications, monitoring (during pregnancy and labour) and improved operating conditions. The rate of high-births is becoming higher. The obstetrician, in order to give birth to "a child" in the best possible conditions while guaranteeing the life of the mother, made the indications of caesarean section much wider [6]. The most frequent indications were: Bone dystocia: it was the main indication of cesarean section in our series with $90 \%$ of our caesarean section indications in Cases compared to $60 \%$ in Witnesses: the difference is statistically significant p-10 ${ }^{-7}$; OR-17.41 [5.42 - 88.44]. Various results were reported by: Togora M. [9] had recovered $50 \%$ and Tegueté I. [10] 32\%. It is a nosological entity that hinders the progression of fetal mobile in the pelvic pathway. Acute fetal suffering: It was the primary fetal indication of cesarean section in our series with a frequency of $30 \%$ in Witnesses with a significant statistical difference (p-10-7 OR-0.00 [0.00 - 0.09]). Similar studies have been carried out by other authors such as: Togora M. [9]: 41.8\% of cases of acute fetal suffering. Cissé B. [13]: 18\%. Tegueté I. [10] 10.4\%. Our rate is justified by the delay in the evacuation of parturients and particularly the lack of qualified staff in community health centres. Any factor that may delay the evacuation of the parturients involves the maternal-fetal prognosis. Scarring uteruses were found in $10 \%$ of cases and preeclampsia in $5 \%$ of Witnesses $\left(\mathrm{p}-10^{-7}\right.$ OR-0.00 [0.00 - 0.07]). Poor monitoring of unsafe pregnancies by unqualified agents means that these women who were to benefit from normally prophylactic caesarean sections come to work.

\subsection{Maternal-Fetal Prognosis}

\subsubsection{Fetal Mortality and Morbidity}

$72.5 \%$ of Witness infants were in a state of severe morbidity or born deaths (Apgar score between 0 - 7) and 27.5\% had a good Apgar between 8 - 10 in the first year unlike the Cases, $100 \%$ had an Apgar between $8-10$ in the $1^{\text {st }}$ mn with p- $10^{-7}$; OR-0.00 [0.00 - 0.02]. In our study, we recorded $30 \%$ of perinatal deaths in Witnesses compared to $1 \%$ in cases with $\mathrm{p}-10^{-7}$; GOLD -0.02 [0.00 - 0.14]. 
Other authors have reported the following frequencies: Tegueté I [10]. 24.6\%; Traoré L [15]. 21.1\%. This high rate of perinatal death among Witnesses (evacuated parturients) allows us to say that the fetal prognosis of The Witnesses is much worse compared to the Cases (prophylactic caesarean section), with $\mathrm{p}-10^{-7}$ OR -0.02 [0.00 - 0.14].

\subsubsection{Maternal Prognosis}

During our study, we recorded 16 uterine ruptures in The Witnesses (evacuated parturients); of the 16 uterine ruptures 14 had hystererraphia and 2 had hysterectomy. None of her complications were found in the Cases (prophylactic caesarean section) with p-0.0036. Camara K. [7] had found in his study 3 cases of uterine ruptures ( 2 hystererraphia and 1 hysterectomy). Post-operative complications: Hemorrhagic/anaemia complications were most represented, followed by infectious complications with $15.5 \%$ and $12.5 \%$ respectively in The Controls. Khlass K. [16] and Derbal S. [17] hadfound 26.3\% and 20.8\% infectious complications respectively. Zarouk [18] in Tunisia, Koné and Al. [19] in Mali had the highest rates of anaemia at $40.5 \%$ and $19.7 \%$ respectively. We did not find any complications in the cases: $\mathrm{p}-0.00022 \mathrm{OR}-0.00$ [0.00 - 0.029]. This may be related to the fact that women are held in the Home Necks for a long time before being received in a surgical setting with sometimes complications.

\subsubsection{Length of Hospitalization}

$100 \%$ of cases had a hospital duration of less than or equal to three days compared to $46 \%$ of Witnesses with a statistically significant difference of $10-7.54 \%$ of Witnesses had a hospital duration of more than 3 days. The average length of hospitalization in the cases was 2.01 days \pm 0.1 with extremes of 2 and 3 days. The average length of hospitalization for Witnesses was 4.9 days \pm 3.1 with extremes of 2 and 20 days. Tegueté I. [10] and Cissé B. [13] reported 9.3 days and 8 days respectively. We did not record any maternal deaths.

\section{Conclusion}

Prophylactic caesarean section is a surgical procedure that improves maternal and perinatal prognosis in contrast to emergency caesarean section.

\section{Authors' Contributions}

All the authors participated in the writing of the manuscript. They all approve the final version of the manuscript.

\section{Ethics Authorisation}

The ethics committee's authorization was found prior to the start of the study.

\section{Conflicts of Interest}

The authors declare no conflicts of interest regarding the publication of this paper. 


\section{References}

[1] Quenum, G., Memadji, M., Konan, B.R., Nigue, L. and Welffens-Ekrac (2001) Quality Caesarean: Analysis of Factors and Determinants at Yopougon University Hospital. International Journal of Medical Sciences, 3, 109-115.

[2] Engelmann, P. (1986) Factors Related to the Increasing Caesarean Section Rates for Cephalopelvic Disproportion. American Journal of Obstetrics and Gynecology, 154, 1095-1098. https://doi.org/10.1016/0002-9378(86)90759-3

[3] Demographic Survey and Health MALI II (1996) EDSM-II from 1995-1996. 181.

[4] Racinet, C. and Favier, M. (1984) The Caesarean Section: Indications, Techniques, Complications. Masson, Paris, 185 p.

[5] O'driscol, K. and Foely, M. (1983) Correlation of Decrease in Prenatal Mortality and Increase in C-Section Rates. American Journal of Obstetrics and Gynecology, 61, 1-5.

[6] Dione, D. (2008) Comparative Study between Two Caesarean Section Techniques: Classical Caesarean Section and Misgav Ladach Caesarean Section at the Reference Health Centre of Commune V of the District of Bamako. Thesis of Medicine, Mali.

[7] Camara, K. (2010) Emergency Caesarean Section versus Prophylactic Caesarean Section: Maternal-Fetal Prognosis Case/Control Study at the Reference Health Centre of Commune V of Bamako District, Mali. Thesis of Medicine, No. 367, 89.

[8] Coulibaly, I. (1999) Caesarean in the Obstetric Gynecology Department of the Gabriel Touré Hospital in Bamako from 1992 to 1996 (about 3314 Cases). Thesis of Medicine, Bamako, 78-85.

[9] Togora, M. (2004) Qualitative Study of Caesarean Section at the Reference Health Centre of Commune V of the District of Bamako from 2000-2002 (about 2883 Cases). Med Thesis, Bamako (Mali), M. 44.

[10] Tegueté, I. (1996) Clinical and Epidemiological Study of Caesarean Section at the Maternity Ward of the National Hospital of Point “G” from 1991 to 1993. About a Control Case Study of 1544 Cases. Thesis Med., Bamako, No. 17, 133 p.

[11] National Directorate of Health, Reproductive Health Cell, Caesarean Section Department (2006) Statistical Data on the Evolution of Caesarean Section.

[12] Sissoko, H. (2006) Cimmediate Post-Cesarean Non-Infectious Applications at the Reference Health Centre in Commune V of Bamako District. Thesis of Medicine, Bamako Mali, M-247.

[13] Cissé, B. (2001) Caesarean Section: Clinical, Epidemiological Aspects and Management of Post-Operative Complications in the Obstetric Gynecological Department of the Reference Health Centre of the Commune V. Medicine Thesis, Bamako, Mali, M.

[14] Konate, M. (2001) The Study of Caesarean Sections in the Obstetric Gynecology Department over a 5-Year Period at Gabriel Touré Hospital. Medical Thesis, 05-M-74.

[15] Traoré, L. (2008) Caesarean Section: Maternal-Fetal Prognosis at the San Reference Health Centre. Thesis of Medicine, Mali, M-304.

[16] Khlass, K. (1989) Analytical Study of Caesarean Section Indications and Maternal-Fetal Prognosis on 277 Caesarean Sections Performed at the Maternity Ward of the New Habib Thameur Hospital (April 4, 1987 to January 31, 1989).

[17] Derbal, S. (1991) Per and Postoperative Maternal-Fetal Complications of Caesarean Operations. About 1045 Cases. Thesis of Medicine, No. 128, Tunis.

[18] Zarouk, S. (1996) Complications of Cesarean Section about 1470 Cases. Medical 
Thesis, No. 49, Tunis.

[19] Koné, A.I. (2005) Risk Factors for Post-Cesarean Maternal Complications at HGT. Medicine Thesis, Bamako, 2005-94p-224. 